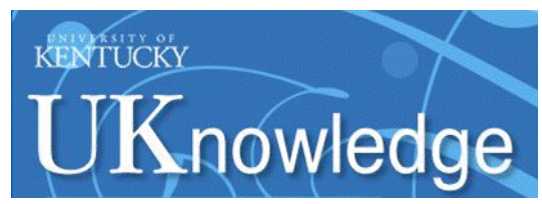

University of Kentucky

UKnowledge

8-31-2017

\title{
Increasing Use of Allogeneic Hematopoietic Cell Transplantation in Patients Aged 70 Years and Older in the United States
}

\author{
Lori Muffly \\ Stanford University \\ Marcelo C. Pasquini \\ Medical College of Wisconsin \\ Michael Martens \\ Medical College of Wisconsin \\ Ruta Brazauskas \\ Medical College of Wisconsin \\ Xiaochun Zhu \\ Medical College of Wisconsin \\ Follow this and additional works at: https://uknowledge.uky.edu/internalmedicine_facpub \\ Part of the Diseases Commons, and the Internal Medicine Commons \\ See next page for additional authors \\ Right click to open a feedback form in a new tab to let us know how this document benefits you.
}

\section{Repository Citation}

Muffly, Lori; Pasquini, Marcelo C.; Martens, Michael; Brazauskas, Ruta; Zhu, Xiaochun; Adekola, Kehinde; Aljurf, Mahmoud; Ballen, Karen K.; Bajel, Ashish; Baron, Frederic; Battiwalla, Minoo; Beitinjaneh, Amer; Cahn, Jean-Yves; Carabasi, Mathew; Chen, Yi-Bin; Chhabra, Saurabh; Ciurea, Stefan; Copelan, Edward; D'Souza, Anita; Edwards, John; Foran, James; Freytes, Cesar O.; Fung, Henry C.; Gale, Robert Peter; Giralt, Sergio; Hashmi, Shahrukh K.; Hildebrandt, Gerhard C.; Ho, Vincent; Jakubowski, Ann; and Lazarus, Hillard, "Increasing Use of Allogeneic Hematopoietic Cell Transplantation in Patients Aged 70 Years and Older in the United States" (2017). Internal Medicine Faculty Publications. 165.

https://uknowledge.uky.edu/internalmedicine_facpub/165

This Article is brought to you for free and open access by the Internal Medicine at UKnowledge. It has been accepted for inclusion in Internal Medicine Faculty Publications by an authorized administrator of UKnowledge. For more information, please contact UKnowledge@lsv.uky.edu. 


\title{
Increasing Use of Allogeneic Hematopoietic Cell Transplantation in Patients Aged 70 Years and Older in the United States
}

\author{
Digital Object Identifier (DOI) \\ https://doi.org/10.1182/blood-2017-03-772368 \\ Notes/Citation Information \\ Published in Blood, v. 130, no. 9, p. 1156-1164.
}

\begin{abstract}
This research was originally published in Blood. Lori Muffly, Marcelo C. Pasquini, Michael Martens, Ruta Brazauskas, Xiaochun Zhu, Kehinde Adekola, Mahmoud Aljurf, Karen K. Ballen, Ashish Bajel, Frederic Baron, Minoo Battiwalla, Amer Beitinjaneh, Jean-Yves Cahn, Mathew Carabasi, Yi-Bin Chen, Saurabh Chhabra, Stefan Ciurea, Edward Copelan, Anita D'Souza, John Edwards, James Foran, Cesar O. Freytes, Henry C. Fung, Robert Peter Gale, Sergio Giralt, Shahrukh K. Hashmi, Gerhard C. Hildebrandt, Vincent Ho, Ann Jakubowski, Hillard Lazarus, Marlise R. Luskin, Rodrigo Martino, Richard Maziarz, Philip McCarthy, Taiga Nishihori, Rebecca Olin, Richard F. Olsson, Attaphol Pawarode, Edward Peres, Andrew R. Rezvani, David Rizzieri, Bipin N. Savani, Harry C. Schouten, Mitchell Sabloff, Matthew Seftel, Sachiko Seo, Mohamed L. Sorror, Jeff Szer, Baldeep M. Wirk, William A. Wood and Andrew Artz. Increasing use of allogeneic hematopoietic cell transplantation in patients aged 70 years and older in the United States. Blood. 2017;130:1156-1164. (c) the American Society of Hematology.
\end{abstract}

The copyright holder has granted the permission for posting the article here.

Due to the large number of authors, only the first 30 and the authors affiliated with the University of Kentucky are listed in the author section above. For the complete list of authors, please download this article or visit: https://doi.org/10.1182/blood-2017-03-772368

\section{Authors}

Lori Muffly, Marcelo C. Pasquini, Michael Martens, Ruta Brazauskas, Xiaochun Zhu, Kehinde Adekola, Mahmoud Aljurf, Karen K. Ballen, Ashish Bajel, Frederic Baron, Minoo Battiwalla, Amer Beitinjaneh, JeanYves Cahn, Mathew Carabasi, Yi-Bin Chen, Saurabh Chhabra, Stefan Ciurea, Edward Copelan, Anita D'Souza, John Edwards, James Foran, Cesar O. Freytes, Henry C. Fung, Robert Peter Gale, Sergio Giralt, Shahrukh K. Hashmi, Gerhard C. Hildebrandt, Vincent Ho, Ann Jakubowski, and Hillard Lazarus 


\title{
TRANSPLANTATION
}

\section{Increasing use of allogeneic hematopoietic cell transplantation in patients aged 70 years and older in the United States}

\author{
Lori Muffly, ${ }^{1}$ Marcelo C. Pasquini, ${ }^{2}$ Michael Martens, ${ }^{3}$ Ruta Brazauskas, ${ }^{2,3}$ Xiaochun Zhu, ${ }^{2}$ Kehinde Adekola, ${ }^{4}$ \\ Mahmoud Aljurf, ${ }^{5}$ Karen K. Ballen, ${ }^{6}$ Ashish Bajel, ${ }^{7}$ Frederic Baron, ${ }^{8}$ Minoo Battiwalla, ${ }^{9}$ Amer Beitinjaneh, ${ }^{10}$ \\ Jean-Yves Cahn, ${ }^{11}$ Mathew Carabasi, ${ }^{12}$ Yi-Bin Chen, ${ }^{13}$ Saurabh Chhabra, ${ }^{14}$ Stefan Ciurea, ${ }^{15,16}$ Edward Copelan, ${ }^{17}$ \\ Anita D'Souza, ${ }^{2}$ John Edwards, ${ }^{18}$ James Foran, ${ }^{19}$ Cesar O. Freytes, ${ }^{20}$ Henry C. Fung, ${ }^{21}$ Robert Peter Gale, ${ }^{22}$ Sergio Giralt, ${ }^{23}$ \\ Shahrukh K. Hashmi, ${ }^{24,25}$ Gerhard C. Hildebrandt, ${ }^{26}$ Vincent Ho, ${ }^{27}$ Ann Jakubowski, ${ }^{23}$ Hillard Lazarus, ${ }^{28}$ Marlise R. Luskin, ${ }^{29}$ \\ Rodrigo Martino, ${ }^{30}$ Richard Maziarz, ${ }^{31}$ Philip McCarthy, ${ }^{32}$ Taiga Nishihori, ${ }^{33}$ Rebecca Olin, ${ }^{34}$ Richard F. Olsson, ${ }^{35,36}$ \\ Attaphol Pawarode, ${ }^{37}$ Edward Peres ${ }^{38}$ Andrew R. Rezvani, ${ }^{1}$ David Rizzieri, ${ }^{39}$ Bipin N. Savani, ${ }^{40}$ Harry C. Schouten, ${ }^{41}$ \\ Mitchell Sabloff, ${ }^{42}$ Matthew Seftel, ${ }^{43}$ Sachiko Seo, ${ }^{44}$ Mohamed L. Sorror ${ }^{45,46}$ Jeff Szer, ${ }^{47}$ Baldeep M. Wirk, ${ }^{48}$ \\ William A. Wood, ${ }^{49}$ and Andrew Artz ${ }^{50}$
}

\begin{abstract}
${ }^{1}$ Division of Blood and Marrow Transplantation, Stanford University, Stanford, CA; ${ }^{2}$ Center for International Blood and Marrow Transplant Research and ${ }^{3}$ Division of Biostatistics, Institute for Health and Society, Medical College of Wisconsin, Milwaukee, WI; ${ }^{4}$ Northwestern Memorial Hospital, Chicago, IL; ${ }^{5}$ Department of Oncology, King Faisal Specialist Hospital Center and Research, Riyadh, Saudi Arabia; ${ }^{6}$ Department of Hematology/Oncology, Massachusetts General Hospital, Boston, MA; ${ }^{7}$ Royal Melbourne Hospital, Victoria, VIC, Australia; ${ }^{8}$ Centre Hospitalier Universitaire de Liege, Domaine Universitaire du Sart Tilman, Liege, Belgium; ${ }^{9} \mathrm{Hematology}$ Branch, National Heart, Lung, and Blood Institute, Bethesda, MD; ${ }^{10}$ Department of Hematology and Oncology, University of Miami, Miami, FL; ${ }^{11}$ Department of Hematology, University Hospital, Grenoble, France; ${ }^{12}$ Department of Medical Oncology, Thomas Jefferson University Hospital, Philadelphia, PA; ${ }^{13}$ Division of Hematology/Oncology, Massachusetts General Hospital, Boston, MA; ${ }^{14}$ Department of Hematology and Oncology, Medical College of Wisconsin, Milwaukee, WI; ${ }^{15}$ Department of Stem Cell Transplantation and Cellular Therapy and ${ }^{16}$ Transplant Myeloid Study Group, The University of Texas MD Anderson Cancer Center, Houston, TX; ${ }^{17}$ Department of Hematologic Oncology and Blood Disorders, Levine Cancer Institute, Carolinas HealthCare System, Charlotte, NC; ${ }^{18}$ Indiana Blood and Marrow Transplantation, Indianapolis, IN; ${ }^{19}$ Mayo Clinic, Jacksonville, FL; ${ }^{20} \mathrm{Texas}$ Transplant Institute, San Antonio, TX; ${ }^{21}$ Department of Medical Oncology, Fox Chase Cancer Center, Temple Health, Philadelphia, PA; ${ }^{22}$ Hematology Research Centre, Division of Experimental Medicine, Department of Medicine, Imperial College London, London, United Kingdom; ${ }^{23} \mathrm{Memorial}$ Sloan Kettering Cancer Center, New York, NY; ${ }^{24}$ Department of Internal Medicine, Mayo Clinic, Minneapolis, MN; ${ }^{25}$ Oncology Center, King Faisal Specialist Hospital and Research Center, Riyadh, Saudi Arabia; ${ }^{26}$ Department of Internal Medicine, University of Kentucky Chandler Medical Center, Lexington, KY; ${ }^{27}$ Center for Hematologic Oncology, Dana-Farber Cancer Institute, Boston, MA; ${ }^{28}$ Seidman Cancer Center, University Hospitals Cleveland Medical Center, Cleveland, OH; ${ }^{29}$ Abramson Cancer Center, University of Pennsylvania Medical Center, Philadelphia, PA; ${ }^{30}$ Divison of Clinical Hematology, Hospital de la Santa Creu i Sant Pau, Barcelona, Spain; ${ }^{31}$ Adult Blood and Marrow Stem Cell Transplant Program, Knight Cancer Institute, Oregon Health and Science University, Portland, OR; ${ }^{32}$ Blood and Marrow Transplant Program, Department of Medicine, Roswell Park Cancer Institute, Buffalo, NY; ${ }^{33}$ Department of Blood and Marrow Transplantation, H. Lee Moffitt Cancer Center and Research Institute, Tampa, FL; ${ }^{34}$ Department of Medicine, University of California San Francisco Medical Center, San Francisco, CA; ${ }^{35}$ Division of Therapeutic Immunology, Department of Laboratory Medicine, Karolinska Institutet, Stockholm, Sweden; ${ }^{36} \mathrm{Center}$ for Clinical Research Sormland, Uppsala University, Uppsala, Sweden; ${ }^{37}$ Blood and Marrow Transplantation Program, Division of Hematology/Oncology, Department of Internal Medicine, The University of Michigan Medical School, Ann Arbor, MI; ${ }^{38}$ Bone Marrow Transplant Program, Henry Ford Hospital, Detroit, $\mathrm{MI} ;{ }^{39}$ Division of Hematologic Malignancies and Cellular Therapy, Blood and Marrow Transplant Clinic, Duke University, Durham, NC; ${ }^{40}$ Division of Hematology/ Oncology, Department of Medicine, Vanderbilt University Medical Center, Nashville, TN; ${ }^{41}$ Department of Hematology, Academische Ziekenhuis, Maastricht, The Netherlands; ${ }^{42}$ Division of Hematology, Department of Medicine, University of Ottawa and Ottawa Hospital Research Institute, Ottawa, ON, Canada; ${ }^{43}$ Department of Medical Oncology and Hematology, CancerCare Manitoba, Winnipeg, MB, Canada; ${ }^{44}$ National Cancer Research Center, East Hospital, Kashiwa, Chiba, Japan; ${ }^{45} \mathrm{Clinical}$ Research Division, Fred Hutchinson Cancer Research Center, Seattle, WA; ${ }^{46}$ Division of Medical Oncology, Department of Medicine, University of Washington School of Medicine, Seattle, WA; ${ }^{47}$ Department Clinical Haematology and Bone Marrow Transplantation, Royal Melbourne Hospital, Victoria, VIC, Australia; ${ }^{48}$ Division of Bone Marrow Transplant, Seattle Cancer Care Alliance, Seattle, WA; ${ }^{49}$ Division of Hematology/Oncology, Department of Medicine, University of North Carolina at Chapel Hill, Chapel Hill, NC; and ${ }^{50}$ Section of Hematology/Oncology, University of Chicago School of Medicine, Chicago, IL
\end{abstract}

\section{Key Points}

- Over the last decade, allogeneic HCT has been increasingly administered in the United States to adults aged 70 and older with hematologic malignancies.
- Allogeneic transplant outcomes were reasonable; high comorbidity and ablative conditioning regimens were associated with inferior outcomes.
Submitted 14 March 2017; accepted 19 June 2017. Prepublished online as Blood First Edition paper, 3 July 2017; DOI 10.1182/blood-2017-03-772368.

The online version of this article contains a data supplement.
The publication costs of this article were defrayed in part by page charge payment. Therefore, and solely to indicate this fact, this article is hereby marked "advertisement" in accordance with 18 USC section 1734. 
In this study, we evaluated trends and outcomes of allogeneic hematopoietic cell transplantation (HCT) in adults $\geq 70$ years with hematologic malignancies across the United States. Adults $\geq 70$ years with a hematologic malignancy undergoing first allogeneic HCT in the United States between 2000 and 2013 and reported to the Center for International Blood and Marrow Transplant Research were eligible. Transplant utilization and transplant outcomes, including overall survival (OS), progression-free survival (PFS), and transplant-related mortality (TRM) were studied. One thousand one hundred and six patients $\geq 70$ years underwent HCT across 103 transplant centers. The number and proportion of allografts performed in this population rose markedly over the past decade, accounting for $0.1 \%$ of transplants in 2000 to $3.85 \%(N=298)$ in 2013 . Acute myeloid leukemia and myelodysplastic syndromes represented the most common disease indications. Two-year OS and PFS significantly improved over time (OS: $26 \%$ [95\% confidence interval (Cl), $21 \%$ to $33 \%$ ] in 2000-2007 to $39 \%$ [ $95 \% \mathrm{Cl}, 35 \%$ to $42 \%$ ] in $2008-2013, P<.001$; PFS: $22 \%$ [ $16 \%$ to $28 \%$ ] in $2000-2007$ to $32 \%$ [95\% Cl, 29\% to $36 \%$ ] in 2008-2013, $P=.003)$. Two-year TRM ranged from $33 \%$ to $35 \%$ and was unchanged over time $(P=.54)$. Multivariable analysis of OS in the modern era of 2008-2013 revealed higher comorbidity by HCT comorbidity index $\geq 3$ (hazard ratio [HR], 1.27; $P=.006)$, umbilical cord blood graft (HR, 1.97; $P=.0002)$, and myeloablative conditioning $(\mathrm{HR}, 1.61 ; P=.0002)$ as adverse factors. Over the past decade, utilization and survival after allogeneic transplant have increased in patients $\geq 70$ years. Select adults $\geq 70$ years with hematologic malignancies should be considered for transplant. (Blood. 2017;130(9):1156-1164)

\section{Introduction}

Allogeneic hematopoietic cell transplantation (HCT) offers the best potential for prolonged disease control for many hematologic malignancies. Historically, older adults were not considered candidates out of concern for increased toxicity and mortality, ${ }^{1}$ thus excluding the majority of hematologic malignancy patients who may have gained benefit. In recent years, the development of reduced-intensity conditioning (RIC) and nonmyeloablative (NMA) regimens, ${ }^{2}$ coupled with improvements in supportive care measures ${ }^{3}$ and more accurate HLA typing methods, ${ }^{4}$ has broadened the application of HCT to include older adults. As such, 22\% of HCT recipients for malignant diseases from 2007 to 2013 reported to the Center for International Blood and Marrow Transplant Research (CIBMTR) were $>60$ years of age. ${ }^{5}$

The feasibility of HCT in adults $>50$ years of age, and even those $>65$ years, has been detailed in several reports. ${ }^{6-11}$ In a registry analysis of patients with acute myeloid leukemia (AML) in first remission or myelodysplastic syndrome (MDS) receiving RIC allogeneic transplants, no significant differences in outcomes were uncovered among HCT recipients aged 40 to 50 years versus those $>65$ years. ${ }^{7}$ Similar results have been reported in multicenter series from the United States and the European Society for Blood and Marrow Transplantation, where disease status and medical comorbidities, rather than chronological age, appear to predict for outcomes. ${ }^{6,8,11}$

Although most studies conclude that older age alone should not preclude transplant, very limited data exist regarding patients transplanted in their eighth decade. ${ }^{12}$ This population is of particular interest, as it has been shown that for each 5-year increase in age beyond 65 years, the proportion of cancer patients with comorbidity, disability, and/or geriatric syndromes increases by $3 \%$ to $5 \%,{ }^{13,14}$ prompting recommendations to perform a comprehensive geriatric assessment for all cancer patients in this age group. ${ }^{15}$ Further, as the population continues to age, with $50 \%$ of all cancers and $70 \%$ of cancer mortality occurring in adults $\geq 65$ years, the number of patients considered for HCT in their eighth decade will continue to rise. ${ }^{16}$

We therefore conducted an observational study of allogeneic HCT recipients $\geq 70$ years reported to the CIBMTR between 2000 and 2013 with the aims of describing transplant utilization as well as baseline characteristics, outcomes, and prognostic factors for this understudied cohort of HCT recipients.

\section{Methods}

\section{Data sources}

The CIBMTR is a research collaboration between the National Marrow Donor Program/Be The Match and the Medical College of Wisconsin. The CIBMTR represents an international network of transplant centers that submit transplantrelated data for patients. It has been collecting HCT outcomes data for $>40$ years and has an extensive database of detailed patient-, transplant-, and disease-related information with prospectively collected longitudinal data. ${ }^{17}$ CIBMTR data are collected in compliance with Health Insurance Portability and Accountability Act regulations and with all applicable federal regulations pertaining to the protection of human research participants, as determined by a continuous review by the National Marrow Donor Program institutional review board and the Medical College of Wisconsin.

The CIBMTR collects 2 levels of data: registration-level data are retrieved from Transplant Essential Data forms, and additional research level data are collected using Comprehensive Report Forms (CRFs). The latter is a subset of the former; patients for whom CRF-level data are collected are chosen through a selection algorithm, as these forms are longer and require more extensive data, including detailed disease information. Thus, the objective of this study included assessing transplant practices and activity in the United States using Transplant Essential Data-level data. Additional analysis with more detailed diseasespecific information was performed in a subset of this population as described in statistical section below.

\section{Patient population}

Patients aged $\geq 70$ years at time of first allogeneic HCT occurring between 2000 and 2013 and reported to the CIBMTR were included. Exclusion criteria included syngeneic donor transplant and patients reported to the CIBMTR who received HCT outside of the United States.

\section{Definitions and outcomes}

Disease status at time of transplant followed CIBMTR disease risk classification ${ }^{18}$ : early disease (acute leukemia in first complete remission, myelodysplastic syndromes with $<5 \%$ blasts, or chronic-phase chronic myeloid leukemia [CML]), intermediate disease (second or greater complete remission acute leukemia, accelerated-phase CML), and advanced disease (acute leukemia not in remission, myelodysplastic syndromes with $\geq 5 \%$ marrow blasts, or blast-phase CML); lymphomas were classified according to chemotherapy sensitivity (sensitive or resistant at time of transplant). Patients with AML were also described in greater detail using CRF data to report disease characteristics of interest, including frequency of favorable, intermediate, and poor cytogenetic categories and presence or absence of FLT3 mutations. Conditioning regimen intensity followed CIBMTR working definitions (myeloablative vs RIC/NMA) ${ }^{19,20}$; due to data capture constraints, RIC and NMA were grouped together. Comorbidity was scored using the HCT comorbidity index; recipient HCT-comorbidity index scores have been routinely reported to the CIBMTR on all allogeneic HCT recipients since 2008. Performance status was captured by the Karnofsky Performance Scale (KPS). Disease Risk Index (DRI) ${ }^{21}$ was evaluated in the entire population and categorized in a subset of patients with all available elements. HLA-matched unrelated donors required 8/8 matching at HLA-A, HLA-B, HLA-C, and HLA-DRB1 at high resolution. Mismatched related donors included haploidentical donors as well as single-antigen and allele mismatches 


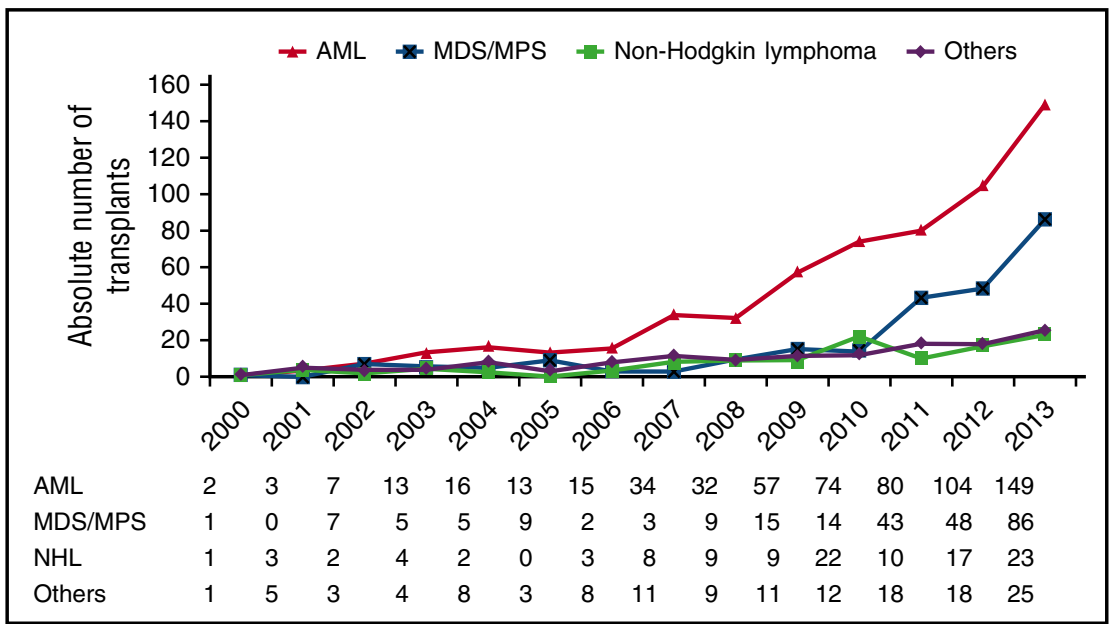

Figure 1. Annual number of HCTs in patients 70 years and older by indication. MPS, myeloproliferative syndrome.

(ie, 7 of 8). Neutrophil engraftment was defined as neutrophil count above $500 / \mu \mathrm{L}$ for 3 consecutive days. Graft-versus-host disease (GVHD) was defined as acute GHVD (grades II-IV or III-IV according to maximum organ stage) or chronic GVHD.

The primary outcome for this study was overall survival (OS), defined as death from any cause; patients for whom death was not observed were censored at the time of last follow-up. Transplant-related mortality (TRM) was defined as death in the absence of disease relapse or progression. The composite end point of progression-free survival (PFS) required either disease relapse or progression or death; patients alive without such events were censored at the time of last follow up. Primary cause of death for each patient was reported by the treating center.

\section{Statistical analysis}

Descriptive statistics summarized the baseline patient, disease, and transplantrelated characteristics according to two time cohorts during the study period (2000 to 2007, 2008 to 2013). The proportion of transplants performed in patients 70 years of age and older relative to all transplants performed in the United States was computed. Univariate summary measures for all outcomes were calculated and compared over the two time periods. Probabilities of OS and PFS were calculated using the Kaplan-Meier estimator, and comparisons between groups were performed using log-rank and point-wise tests. Probabilities of neutrophil engraftment, GVHD, TRM, and disease relapse/progression were calculated by cumulative incidence function accounting for competing risks. Comparisons of cumulative incidence across time cohorts were performed via Gray's test.

Prognostic factor analysis was performed on 3 patient subsets. The first analysis included all patients $\geq 70$ years transplanted between 2008 and 2013 with the intention of focusing on a contemporary cohort of patients with all disease indications who received comorbidity assessment by the HCTcomorbidity index (which was not available prior to 2008). For this subset, a multivariable Cox proportional hazards regression model was built using stepwise variable selection to evaluate patient, disease, and transplant variables associated with OS. The variables analyzed were age ( $70-74$ and $\geq 75$ years), gender, HCT-comorbidity index $\left(0-2\right.$ and $\geq 3$ ), ${ }^{22}$ KPS (modeled at $\geq 80 \%$ and $\geq 80 \%$ ), disease, disease status, donor type (HLA-matched sibling, HLAmismatched related, and HLA matched unrelated donor, divided according to donor age $[<30$ and $\geq 30$ years] or mismatched unrelated donor, unrelated donor with HLA-matching unknown, and umbilical cord blood), conditioning regimen intensity ${ }^{19,20}$ graft source (bone marrow, mobilized peripheral blood stem cells, and umbilical cord blood), year of transplant, donor-recipient gender match, donor-recipient cytomegalovirus serologic status, and GVHD prophylaxis (calcineurin inhibitor and methotrexate, calcineurin inhibitor and mycophenolate mofetil, and calcineurin inhibitor with other combinations and other regimens).

The second subset analysis explored variables associated with OS and TRM among patients $\geq 70$ years with controlled disease entering transplant. This subset included patients with early or intermediate-risk AML (ie, patients in complete remission 1 [CR1] or CR2 as opposed to active disease), MDS with $<5 \%$ blasts, and chemosensitive non-Hodgkin lymphoma (NHL) who underwent HCT between 2008 and 2013. This more homogenous subset included the most common disease indications for HCT among older adults and enabled analysis of variables associated with TRM without confounding from less common transplant disease indications. Multivariable Cox regression models were constructed by testing the covariates as above with the exception of disease status as all patients in this subset had early or intermediate disease at transplant.

The third subset focused on exploring outcomes by comorbidity and disease status in patients with AML and MDS undergoing transplant between 2008 and 2013. For this subset, probabilities of OS and TRM were calculated as above.

For multivariable analysis performed in the first and second subsets, all covariates associated with outcome at $P<.05$ were retained in the final models and considered significant. Tests of proportionality for each covariate and of interaction between covariates were performed; no violations of proportionality or significant interactions were found. All analyses were performed using SAS 9.2 (SAS Institute, Cary, NC).

\section{Results}

\section{HCT utilization for adults $\mathbf{7 0}$ years and older over time}

A total of 1106 patients $\geq 70$ years underwent first allogeneic HCT in the United States and were reported to the CIBMTR between 2000 and 2013. The absolute number of transplants for adults $\geq 70$ years increased substantially over that time, from 5 in 2000 to 283 in 2013. The proportion of allogeneic HCT recipients $\geq 70$ years also increased over time, from $0.1 \%$ in 2000 to $3.85 \%$ in 2013 . Further, the absolute number of transplant programs performing allogeneic HCT in patients $\geq 70$ years increased from 65 centers in 2000-2007 to 93 centers in 2008-2013. Transplant for AML and MDS accounted for the main indications across time periods (Figure 1).

\section{Patient and HCT characteristics}

Baseline patient demographics and transplant characteristics stratified by HCT time period for all patients in the dataset are described in Table 1 . The median age at time of HCT was 72 (range, 70-84 years). KPS was $<80 \%$ in $9 \%$ of the patients. Comorbidity by HCTcomorbidity index (captured for recipients transplanted from 2008 to 2013) demonstrated high HCT-comorbidity index of $\geq 3$ in $46 \%$ of patients; $16 \%$ had HCT-comorbidity index scores of $\geq 5$. Among patients with available DRI, the majority received transplant with intermediate risk. The donor source shifted from related donors in $51 \%$ in the initial time period to $70 \%$ unrelated grafts in the later time period, 
Table 1. Demographics of patients 70 years and older who received HCT from 2000 to 2013

\begin{tabular}{|c|c|c|c|}
\hline & $\begin{array}{l}\text { 2000-2007, } \\
\text { n (\%) }\end{array}$ & $\begin{array}{l}\text { 2008-2013, } \\
\text { n (\%) }\end{array}$ & $\begin{array}{l}\text { All patients, } \\
\mathrm{n}(\%)\end{array}$ \\
\hline No. of patients & 207 & 899 & 1106 \\
\hline No. of centers & 65 & 93 & 103 \\
\hline \multicolumn{4}{|l|}{ Age at transplant, $y$} \\
\hline Median (range) & $72(70-83)$ & $72(70-84)$ & $72(70-84)$ \\
\hline $70-74$ & $176(85)$ & $807(90)$ & $983(89)$ \\
\hline $75-79$ & $27(13)$ & $88(10)$ & $115(10)$ \\
\hline$\geq 80$ & $4(2)$ & $4(<1)$ & $8(1)$ \\
\hline \multicolumn{4}{|l|}{ Sex } \\
\hline Male & $151(73)$ & $629(70)$ & $780(71)$ \\
\hline Female & $56(27)$ & $270(30)$ & $326(29)$ \\
\hline \multicolumn{4}{|l|}{ KPS } \\
\hline$<80 \%$ & $17(8)$ & $87(10)$ & $104(9)$ \\
\hline$\geq 80 \%$ & $119(57)$ & $784(87)$ & $903(82)$ \\
\hline Missing & $71(34)$ & $28(3)$ & $99(9)$ \\
\hline \multicolumn{4}{|l|}{ HCT-comorbidity index } \\
\hline 0 & - & $248(28)$ & $248(22)$ \\
\hline $1-2$ & - & $234(26)$ & $234(21)$ \\
\hline$\geq 3$ & - & $417(46)$ & $417(38)$ \\
\hline Missing ${ }^{*}$ & 207 & 0 & $207(19)$ \\
\hline \multicolumn{4}{|l|}{ Disease } \\
\hline AML & $103(50)$ & $496(55)$ & $599(54)$ \\
\hline ALL & $2(<1)$ & $23(3)$ & $25(2)$ \\
\hline CLL/PLL & $22(11)$ & $54(6)$ & $76(7)$ \\
\hline CML & $5(2)$ & $6(<1)$ & $11(<1)$ \\
\hline MDS/MPS & $32(15)$ & $215(24)$ & $247(22)$ \\
\hline Other acute leukemia & $1(<1)$ & $8(<1)$ & $9(<1)$ \\
\hline NHL & $23(11)$ & $90(10)$ & $113(10)$ \\
\hline Plasma cell disorder/multiple myeloma & $10(5)$ & $2(<1)$ & $12(1)$ \\
\hline Other malignancies & $3(1)$ & 0 & $3(<1)$ \\
\hline Severe aplastic anemia & $4(2)$ & $5(<1)$ & $9(<1)$ \\
\hline $\mathrm{PNH}$ & $2(1)$ & 0 & $2(<1)$ \\
\hline \multicolumn{4}{|l|}{ Disease status } \\
\hline Early disease & $45(22)$ & $355(39)$ & $300(27)$ \\
\hline Intermediate disease & $25(12)$ & $93(10)$ & $118(11)$ \\
\hline Advanced disease & $48(23)$ & $230(26)$ & $278(25)$ \\
\hline NHL sensitive & $10(5)$ & $79(10)$ & $89(9)$ \\
\hline NHL resistant & $6(3)$ & $10(1)$ & $16(1)$ \\
\hline Other (unknown/missing/NA) & $73(35)$ & $132(15)$ & $205(19)$ \\
\hline \multicolumn{4}{|l|}{ DRI† } \\
\hline Low & $6(3)$ & $32(4)$ & $38(3)$ \\
\hline Intermediate & $28(14)$ & $152(17)$ & $180(16)$ \\
\hline High & $20(10)$ & $115(13)$ & $135(12)$ \\
\hline Very high & 7 (3) & $18(2)$ & $25(2)$ \\
\hline Other (missing/NA) & $146(71)$ & $582(65)$ & $728(66)$ \\
\hline \multicolumn{4}{|l|}{ Donor type } \\
\hline Matched related & $93(45)$ & $204(23)$ & $297(27)$ \\
\hline Mismatched related & $13(6)$ & $67(7)$ & $80(7)$ \\
\hline Matched unrelated & $52(25)$ & $463(52)$ & $515(47)$ \\
\hline Mismatched unrelated & $12(6)$ & $68(8)$ & $80(7)$ \\
\hline Unrelated HLA match unknown & $20(10)$ & 46 (5) & $66(6)$ \\
\hline Umbilical cord blood & $7(3)$ & $51(6)$ & $58(5)$ \\
\hline Missing & $10(5)$ & 0 & $10(1)$ \\
\hline $\begin{array}{l}\text { Unrelated donor age, median } \\
\text { (range), y }\end{array}$ & $36(21-60)$ & $30(19-61)$ & $31(19-61)$ \\
\hline $18-30$ & $23(27)$ & $278(48)$ & $301(46)$ \\
\hline $31-40$ & $24(29)$ & $139(24)$ & $163(25)$ \\
\hline $41-50$ & $21(25)$ & $96(17)$ & $117(18)$ \\
\hline $51-61$ & $5(6)$ & $25(4)$ & $30(5)$ \\
\hline Unknown & $11(13)$ & $39(7)$ & $50(8)$ \\
\hline \multicolumn{4}{|l|}{ Graft source } \\
\hline Bone marrow & $17(8)$ & $93(10)$ & $110(10)$ \\
\hline Peripheral blood & $183(88)$ & $755(84)$ & $938(85)$ \\
\hline Umbilical cord blood & $7(3)$ & $51(6)$ & $58(5)$ \\
\hline
\end{tabular}

Table 1. (continued)

\begin{tabular}{|c|c|c|c|}
\hline & $\begin{array}{c}2000-2007 \\
\text { n (\%) }\end{array}$ & $\begin{array}{c}\text { 2008-2013 } \\
\text { n (\%) }\end{array}$ & $\begin{array}{c}\text { All patients, } \\
\text { n (\%) }\end{array}$ \\
\hline \multicolumn{4}{|c|}{ Donor-recipient sex match } \\
\hline Male-male & $95(46)$ & $388(43)$ & $483(44)$ \\
\hline Male-female & $25(12)$ & $154(17)$ & $179(16)$ \\
\hline Female-male & $50(24)$ & $203(23)$ & $253(23)$ \\
\hline Female-female & $30(14)$ & $98(11)$ & $128(12)$ \\
\hline Unknown & 7 (3) & $56(6)$ & $63(6)$ \\
\hline \multicolumn{4}{|c|}{ Donor-recipient CMV status } \\
\hline Positive-positive & $16(8)$ & $269(30)$ & $285(26)$ \\
\hline Positive-negative & $7(3)$ & $67(7)$ & $74(7)$ \\
\hline Negative-positive & $37(18)$ & $292(32)$ & $329(30)$ \\
\hline Negative-negative & $13(6)$ & $176(20)$ & $189(17)$ \\
\hline Unknown & $134(65)$ & $95(11)$ & $229(21)$ \\
\hline \multicolumn{4}{|l|}{ Regimen intensity } \\
\hline Ablative & $11(5)$ & $102(11)$ & $113(10)$ \\
\hline RIC/NMA & $178(86)$ & $796(89)$ & $974(88)$ \\
\hline Unknown & $18(9)$ & $1(<1)$ & $19(2)$ \\
\hline \multicolumn{4}{|l|}{ Conditioning regimen } \\
\hline Flu/Bu \pm other & $29(14)$ & $368(41)$ & $397(36)$ \\
\hline Flu/Mel \pm other & $35(17)$ & $137(15)$ & $172(16)$ \\
\hline Flu/TBI \pm other & $65(31)$ & $274(30)$ & $339(31)$ \\
\hline Bu based & $11(5)$ & $17(2)$ & $28(3)$ \\
\hline Flu/Cy \pm other & $26(13)$ & $40(4)$ & $66(6)$ \\
\hline $\mathrm{TBI} / \mathrm{TLI} \pm$ other & $16(8)$ & $49(5)$ & $65(6)$ \\
\hline Other & $17(8)$ & $14(2)$ & $31(3)$ \\
\hline Unknown & $8(4)$ & 0 & $8(<1)$ \\
\hline
\end{tabular}

ALL, acute lymphoblastic leukemia; Bu, busulfan; CLL, chronic lymphocytic leukemia; CMV, cytomegalovirus; Flu/Bu, fludarabine + busulfan; Flu/Mel, fludarabine + melphalan; Flu/TBI, fludarabine + total body irradiation; MPS, myeloproliferative syndrome; NA, not available; PLL, prolymphocytic leukemia; PNH, paroxysmal nocturnal hemoglobinuria; Flu/Cy, fludarabine + cyclophosphamide; $\mathrm{TBI} / \mathrm{TLI}$, total body irradiation or total lymphoid irradiation.

*HCT-comorbidity index was not captured by the CIBMTR registry prior to 2008 . †All elements required to generate the DRI were not available in all patients.

driven mostly be greater use of matched unrelated donors over time. Although most patients received RIC/NMA conditioning regimens, myeloablative regimens were administered to $10 \%$ overall. The more widespread use of fludarabine plus busulfan-based regimens signified the largest change in conditioning regimens over time. Increasing numbers of patients entered transplant with controlled disease in the more recent time period.

Supplemental Table A (available on the Blood Web site) includes additional disease and transplant-related details regarding AML patients transplanted between 2008 and 2013. In this subset of 120 patients with AML with available information, $70 \%$ had intermediate cytogenetics, $85 \%$ of patients with available FLT3 status were wild-type, and $69 \%$ were in morphologic complete remission at time of transplant.

\section{Outcomes}

Unadjusted 1- and 2-year transplant outcome probabilities (neutrophil engraftment, grades II-IV and III-IV acute GVHD, chronic GVHD, TRM, relapse/progression, PFS, and OS) stratified by HCT time period are summarized in Table 2 . Two-year PFS improved significantly from 2000-2007 to 2008-2013 (22\% [95\% confidence interval (CI) $16 \%$ to $28 \%$ ] vs $32 \%$ [ $29 \%$ to $36 \%$ ], $P=.003$ ), while TRM remained static ( $P=.54$ over the entire time period). Two-year OS also improved significantly over time, from $26 \%$ [95\% CI, $21 \%$ to $33 \%$ ] in $2000-2007 \%$ to $39 \%$ [ $95 \%$ CI, $35 \%$ to $42 \%$ ] in $2008-2013, P<.001$ (Figure 2A). Overall and disease-free survival among patients with the most common indications for HCT from 2008 to 2013 and according to DRI in the same period are shown in Figure 2B-E). 
Table 2. Univariate analysis of posttransplant outcomes of patients aged 70 years and older and recipients of an allogeneic HCT from 2000 to 2013

\begin{tabular}{|c|c|c|c|c|}
\hline & $\begin{array}{l}\text { Total cohort } \\
\text { prob. }(95 \% \mathrm{Cl})\end{array}$ & $\begin{array}{c}2000-2007 \\
\text { prob. }(95 \% \mathrm{Cl})\end{array}$ & $\begin{array}{c}2008-2013 \\
\text { prob. }(95 \% \mathrm{Cl})\end{array}$ & $\boldsymbol{P}^{*}$ \\
\hline \multicolumn{5}{|c|}{ Neutrophil engraftment $\dagger$} \\
\hline No. evaluated & - & - & 890 & - \\
\hline $28 \mathrm{~d}$ & - & - & $92(90-93)$ & - \\
\hline \multicolumn{5}{|c|}{ Acute GVHD, grade II-IV } \\
\hline No. evaluated & 427 & 105 & 322 & .63 \\
\hline $100 \mathrm{~d}$ & $32(28-37)$ & $31(23-41)$ & $33(28-38)$ & .82 \\
\hline \multicolumn{5}{|c|}{ Acute GVHD, grade III-IV } \\
\hline No. Evaluated & 427 & 105 & 322 & .05 \\
\hline $100 d$ & $13(10-17)$ & $18(11-26)$ & $12(9-16)$ & .13 \\
\hline \multicolumn{5}{|l|}{ Chronic GVHD } \\
\hline No. evaluated & 1025 & 161 & 864 & .94 \\
\hline $1 \mathrm{y}$ & $32(30-35)$ & $32(25-40)$ & $32(29-36)$ & .97 \\
\hline $2 y$ & $37(34-40)$ & $35(28-43)$ & $38(35-41)$ & .55 \\
\hline \multicolumn{5}{|l|}{ TRM } \\
\hline No. evaluated & 1086 & 192 & 894 & .77 \\
\hline $1 \mathrm{y}$ & $25(23-28)$ & $26(20-33)$ & $25(22-28)$ & .73 \\
\hline $2 y$ & $33(30-36)$ & $35(28-42)$ & $33(29-36)$ & .54 \\
\hline \multicolumn{5}{|c|}{ Relapse/progression } \\
\hline No. evaluated & 1086 & 192 & 894 & .04 \\
\hline $1 \mathrm{y}$ & $32(30-35)$ & $38(31-45)$ & $31(28-34)$ & .09 \\
\hline $2 y$ & $37(34-40)$ & $43(36-50)$ & $35(32-38)$ & .04 \\
\hline \multicolumn{5}{|l|}{ PFS } \\
\hline No. evaluated & 1086 & 192 & 894 & .001 \\
\hline $1 \mathrm{y}$ & $42(39-45)$ & $36(29-43)$ & $44(40-47)$ & .04 \\
\hline $2 y$ & $30(27-33)$ & $22(16-28)$ & $32(29-36)$ & .003 \\
\hline \multicolumn{5}{|l|}{ os } \\
\hline No. evaluated & 1106 & 207 & 899 & $<.001$ \\
\hline $1 \mathrm{y}$ & $50(47-53)$ & $42(35-49)$ & $52(49-56)$ & .007 \\
\hline $2 y$ & $36(33-39)$ & $26(21-33)$ & $39(35-42)$ & $<.001$ \\
\hline
\end{tabular}

Prob., probability.

${ }^{*} P$ value for significance between the 2000-2007 and 2008-2013 cohorts.

†Neutrophil engraftment was not consistently captured prior to 2008 .

The most frequent primary cause of death was relapse/progression of primary disease, which accounted for $46 \%$ of deaths. Infection and GVHD were each reported as the primary cause of death in $10 \%$. Cause of death could not be clarified in $22 \%$ of the patients.

\section{Prognostic factor analysis in modern cohorts}

The first subset analysis focused on all patients $\geq 70$ years transplanted between 2008 and 2013. Significant prognostic factors for inferior survival included high comorbidity defined by HCT-comorbidity index $\geq 3$ (hazard ratio [HR], 1.27; 95\% CI, 1.07-1.51; $P=.006$ ), receipt of cord blood as a donor source (HR, 1.97; 95\% CI, 1.37-2.82; $P=.0002)$ relative to HLA matched sibling donor, and use of a myeloablative conditioning regimen (HR, 1.61; 95\% CI, 1.25-2.08; $P=.0002$ ) (Table 3). All other variables tested in the model, including age, disease status, disease, and KPS, were not found to significantly influence survival.

Table 3 highlights variables significantly associated with TRM and OS among the subset of 416 HCT recipients with early or intermediate AML or MDS or chemosensitive NHL transplanted between 2008 and 2013. Female relative to male recipients (HR, 1.30; 95\% CI, 1.03-1.65; $P=.029)$ and myeloablative conditioning as opposed to RIC/NMA (HR, 1.60; 95\% CI, 1.13-2.28; $P=.009$ ) were associated with higher mortality. Conditioning regimen intensity was the only significant covariate associated with TRM (HR, 2.06; 95\% CI, 1.32-3.22; $P=.001)$ in this subset.

Supplemental Figure 1A-D demonstrates OS and TRM, respectively, for patients with AML or MDS who underwent transplantation between 2008 and 2013 based upon both disease risk at time of transplantation (early/intermediate disease vs advanced disease) and also by comorbidity score (ie, HCT $<3$ vs $\geq 3$ ). High comorbidity in this population appeared to have a greater adverse impact on patients with advanced or active disease at time of transplant as opposed to patients with early or intermediate disease (ie, in remission) at the time of transplant.

\section{Discussion}

In the current observational study, we report on the utilization, characterization and prognostic factors associated with allogeneic HCT in adults $\geq 70$ years. Our findings, derived from a large national cohort of patients transplanted in the United States over the last decade, demonstrate that the absolute number and proportion of allogeneic transplants performed for adults in their eighth decade has risen steadily on a yearly basis since 2000 , such that patients $\geq 70$ years now represent nearly $4 \%$ of allogeneic HCT recipients.

Several factors spurred the increase in transplant volume for this population. The majority of growth was in fact due to increasing numbers of patients with early or intermediate-risk AML or MDS as defined by the CIBMTR (ie, AML in CR1 or greater; MDS with $<5 \%$ blasts) transplanted since 2008. Greater utilization of HCT for MDS beginning after 2010 coincides with the decision in the United States to cover this disease indication for Medicare beneficiaries 

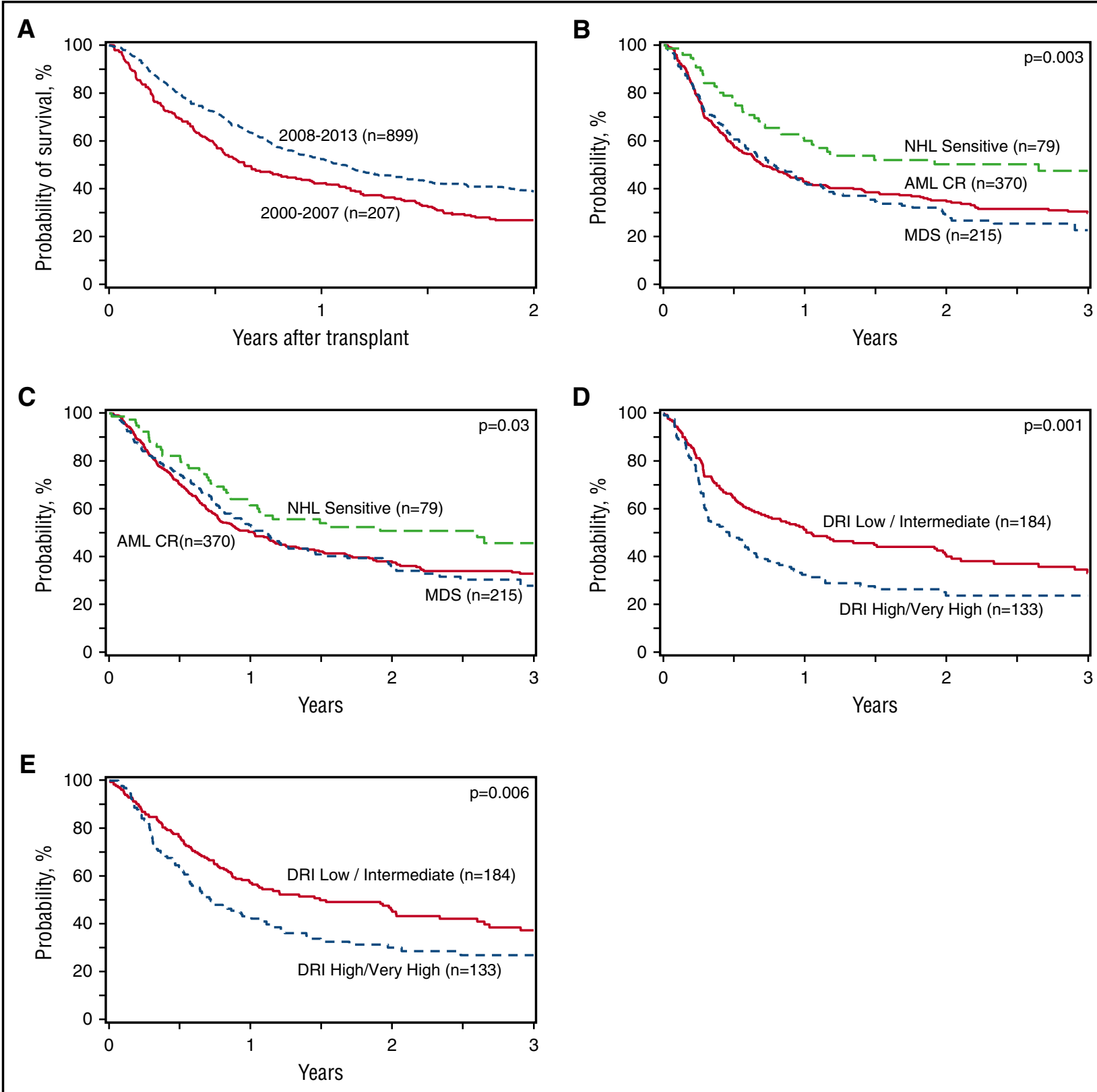

Figure 2. Allogeneic HCT outcomes in adults 70 years and older. (A) OS after HCT in patients $\geq 70$ years by year of transplant (2000-2007 vs 2008-2013). (B) Diseasefree survival after HCT in patients $\geq 70$ years with AML in remission, myelodysplasia, and chemotherapy-sensitive NHL from 2008 to 2013. (C) OS after HCT in patients $\geq 70$ years with AML in remission, myelodysplasia, and chemotherapy-sensitive NHL from 2008 to 2013. (D) Disease-free survival after HCT in patients $\geq 70$ years from 2008 to 2013 according to DRI. (E) OS after HCT in patients $\geq 70$ years from 2008 to 2013 according to DRI.

participating in an approved clinical study through the Center for Medicare and Medicaid Services Coverage with Evidence Development. ${ }^{23}$ Additionally, the increasing use of unrelated donors (and, to some extent, haploidentical or cord blood donor stem cell sources) relative to sibling donors fueled transplant growth by substantially expanding donor availability. Perhaps the most important yet difficult to measure factor is the societal changes that have prompted physician and patient willingness to consider transplant. Similar trends in uptake for older patients have been reported in autologous transplants where donor sources are irrelevant, as well as in solid organ transplantation. ${ }^{24,25}$

Despite increased utilization of HCT for this older adult population, the relatively small number of allogeneic transplants confirms reports by others ${ }^{26,27}$ that the vast majority of adults aged $\geq 70$ years with transplant-eligible hematologic malignancies are not undergoing HCT. For example, according to the National Cancer Institute's Surveillance, Epidemiology, and End Results Program, there are $\sim 3000$ new cases of AML diagnosed per year in adults aged 70 to 79 years in the United States (http://seer.cancer.gov/). Our data reveal that only 253 AML patients aged $\geq 70$ years underwent allogeneic HCT between 2012 and 2013, representing only 4\% of the population of newly diagnosed AML patients in their eighth decade of life. Transplant was even more rarely pursued in this age group for other disease indications, such as NHL $(\mathrm{n}=113)$ and acute lymphoblastic leukemia $(\mathrm{n}=25)$.

The lack of transplant outcome data in this age group has been a major impediment and previously has been restricted to reports 
Table 3. Multivariate models for overall mortality $(1-$ OS) and TRM in patients aged 70 years and older who received an allogeneic HCT

\begin{tabular}{|c|c|c|c|c|}
\hline Effect & No. & HR & $95 \% \mathrm{Cl}$ & $\boldsymbol{P}$ \\
\hline \multicolumn{5}{|c|}{ Overall mortality } \\
\hline \multicolumn{5}{|l|}{ HCT-comorbidity index } \\
\hline $0-2$ & 479 & 1.000 & - & - \\
\hline$\geq 3$ & 415 & 1.269 & $1.070,1.504$ & .0061 \\
\hline Donor type & & & & $.0046^{*}$ \\
\hline HLA-matched, related & 202 & 1.000 & - & - \\
\hline HLA-mismatched, related & 67 & 1.209 & $0.848,1.724$ & .2932 \\
\hline HLA-matched, URD $<=30$ y old & 233 & 0.933 & $0.726,1.199$ & .5874 \\
\hline HLA-matched, URD $>30$ y old & 210 & 1.144 & $0.898,1.457$ & .2754 \\
\hline HLA-matched, URD of unknown age & 19 & 0.838 & $0.425,1.649$ & .6080 \\
\hline HLA-mismatched, URD & 67 & 1.324 & $0.945,1.854$ & .1025 \\
\hline HLA matching unknown, URD & 45 & 1.178 & $0.782,1.775$ & .4340 \\
\hline UCB & 51 & 1.963 & $1.372,2.809$ & .0002 \\
\hline \multicolumn{5}{|l|}{ Conditioning intensity } \\
\hline RIC/NMA & 791 & 1.000 & - & - \\
\hline \multicolumn{5}{|c|}{ Overall mortality for patients with early/intermediate AML/MDS and chemosensitive NHL } \\
\hline \multicolumn{5}{|l|}{ Sex } \\
\hline Male & 359 & 1.00 & - & - \\
\hline Female & 165 & 1.30 & $1.03-1.65$ & .03 \\
\hline \multicolumn{5}{|l|}{ Conditioning intensity } \\
\hline RIC/NMA & 473 & 1.00 & - & \\
\hline MA & 50 & 1.60 & $1.13-2.28$ & .009 \\
\hline \multicolumn{5}{|c|}{ TRM for patients with early/intermediate AML/MDS and chemosensitive NHL } \\
\hline \multicolumn{5}{|l|}{ Conditioning intensity } \\
\hline RIC/NMA & 473 & 1.00 & - & - \\
\hline MA & 50 & 2.06 & $1.32-3.22$ & .001 \\
\hline
\end{tabular}

The first model for overall mortality in a population from 2008 to 2013 and all hematologic malignances. The second multivariate analysis includes models for overall mortality for patients with early/intermediate AML/MDS and chemosensitive NHL and TRM for a subset of patients with early and intermediate AML and MDS who received an allogenic HCT from 2008 to 2013.

MA, myeloablative; UCB, umbilical cord blood; URD, unrelated donor.

${ }^{*}$ Donor type variable was tested with 7 degrees of freedom and divided the group of matched unrelated donor according to donor age divided at the median.

including small numbers of these patients. ${ }^{11,27} \mathrm{We}$ found that transplant survival has significantly improved over time for this older adult population, with 2-year PFS and OS estimates of 32\% (95\% CI, 29\% to $36 \%$ ) and $39 \%$ (95\% CI, 35\% to $42 \%$ ), respectively, for HCT recipients transplanted in the more recent era of 2008-2013. As TRM and severe acute GVHD did not change over time, improvements were likely mediated in part by transplant in patients with less advanced disease. Consistent with this, a greater proportion of patients entered transplant with earlier-risk disease (recognizing many were missing disease risk in earlier years), and improvements occurred in PFS and cumulative incidence of disease relapse.

Given the methodological issues and biases associated with retrospectively comparing treatment approaches, prospective studies are required to effectively evaluate HCT versus non-HCT therapies in older adults for each disease indication. Few studies report outcomes of patients $\geq 70$ years after nontransplant treatment to benchmark these results, and lack of consistent patient health information reported in these studies hinders identification of transplant-eligible subsets. In a population study of AML from the Netherlands, $69 \%$ of patients $\geq 70$ years received some form of chemotherapy, but no patients were allografted, resulting in dismal 1- and 5-year survival rates of $15 \%$ and $2 \%$, respectively, for patients diagnosed between 2007 and $2012 .^{28}$ Thus, our study outcomes for AML patients transplanted between 2008 and 2013, revealing 2-year PFS and OS of $36 \%$ and 38\%, respectively, appear extremely encouraging and suggest that select older patients achieve a substantial disease and survival benefit after HCT.

Concerns regarding treatment-related morbidity and mortality likely account for reluctance to offer transplant to older patients. Our findings that TRM has remained stable over the decade, with 2-year estimates at $30 \%$ to $35 \%$, is similar to the findings of the registry analysis, where 2-year TRM ranged from $25 \%$ to $39 \%$ in adults $\geq 40$ years with AML and MDS following RIC HCT, without significant differences across age groups. ${ }^{7}$ Registry summaries inclusive of heterogeneous disease status, donor type, and conditioning regimen may be less favorable than institutional protocol reports of more selected patients yet reflect present population-based practice patterns and results. Although supportive care for hematologic malignancy and transplant recipients has improved considerably in recent years, so much so as to allow the application of allogeneic HCT to patients $\geq 70$ years, appreciable TRM remains a barrier to transplant utilization and success in this group. Impairments in adaptive immune response with aging are accentuated in the allogeneic transplant setting and likely contribute to the relatively high rates of transplant-related morbidity and mortality in older patients. ${ }^{29}$ Strategies to overcome thymic impairments with aging and allogeneic transplant are of considerable interest. ${ }^{30}$ Higher rates of TRM in those patients 70 years and older with advanced disease and high comorbidity suggest that transplant should be pursued with particularly caution in such patients.

To reduce TRM, we must consider improvements in patient selection and further refine the transplant process to allow for less toxicity and morbidity in older adults. Similar to others, ${ }^{11}$ we found that inferior survival was associated with high comorbidity, albeit with only a modest effect (HR, 1.27; 95\% CI, 1.07-1.51). Patients $\geq 75$ years did not fare significantly worse than those 70 to 74 years of age. Therefore, age alone or moderate degrees of comorbidity are insufficient to determine transplant eligibility. Enhanced discrimination may be obtained with the use of geriatric assessment prior to HCT. ${ }^{31}$ Geriatric assessment for evaluation and guided interventions warrant additional research to abrogate morbidity and mortality. ${ }^{15,32}$ More precise risk stratification for TRM, if not survival, may paradoxically 
expand the number of older patients eligible for transplant by delineating a larger pool of patients with acceptable transplant risks.

Similar to younger patients, disease relapse remains the primary cause of death in older transplant recipients. However, more intensive transplant conditioning via myeloablative regimens was associated with worse OS in the whole cohort and in the subset of early/intermediate AML/MDS and chemosensitive NHL. While new disease scoring systems such as the DRI- and minimal residual disease-based assessments have been used to evaluate relapse risk in younger HCT patients, the importance of these tools in older patients is less established. ${ }^{21,33}$ For example, independent of the DRI, older patients fare worse, and minimal residual disease measures have a less pronounced effect on relapse after NMA transplant for AML and have not been shown to affect survival in this population. ${ }^{33}$ This likely reflects the adverse biology of disease in older age in that even after adjustments for adverse disease features, older adults routinely demonstrate outcomes significantly inferior to those of younger adults. ${ }^{34,35}$ This underscores the need to move to transplant expeditiously after initial treatment-induced response as well as to explore posttransplant maintenance and adoptive immunotherapy approaches following RIC or NMA allogeneic HCT in older adults.

In summary, the utilization of allogeneic HCT in adults aged $\geq 70$ years with hematologic malignancies has markedly increased over the past decade. Nearly $40 \%$ of adults in this age group are alive at 2 years following transplant, suggesting that this approach is feasible, offers promising disease control, and should be considered more frequently for patients in their eighth decade with transplant-eligible diseases.

\section{Acknowledgments}

The CIBMTR is supported primarily by National Institutes of Health public health service grant/cooperative agreement 5U24-CA076518 from the National Cancer Institute; the National Heart, Lung, and Blood Institute, and the National Institute of Allergy and Infectious Diseases; grant/cooperative agreement 5U10HL069294 from the National Heart, Lung, and Blood Institute and the National Cancer Institute; contract HHSH250201200016C with Health Resources and Services Administration (US Department of Health and Human Services); grants N00014-15-1-0848 and N00014-16-12020 from the Office of Naval Research. This work was also funded by grants from Actinium Pharmaceuticals, Inc.,* Alexion, and Amgen, Inc.*; by an anonymous donation to the Medical College of Wisconsin; by Astellas Pharma US, AstraZeneca, Atara Biotherapeutics, Inc., Be the Match Foundation, Bluebird Bio,
Inc.,* Bristol Myers Squibb Oncology,* Celgene Corporation,* Cellular Dynamics International, Inc., Cerus Corporation, Chimerix, Inc., * the Fred Hutchinson Cancer Research Center, Gamida Cell Ltd., Genentech, Inc., Genzyme Corporation, Gilead Sciences, Inc., Health Research, Inc., Roswell Park Cancer Institute, HistoGenetics, Inc., Incyte Corporation, Janssen Scientific Affairs, LLC, Jazz Pharmaceuticals, Inc., * the Jeff Gordon Children's Foundation, The Leukemia \& Lymphoma Society, Medac, GmbH, MedImmune, The Medical College of Wisconsin, Merck \& Co, Inc., * Mesoblast,* MesoScale Diagnostics, Inc., Miltenyi Biotec, Inc., * National Marrow Donor Program, Neovii Biotech NA, Inc., Novartis Pharmaceuticals Corporation, Onyx Pharmaceuticals, Optum Healthcare Solutions, Inc., Otsuka America Pharmaceutical, Inc., Otsuka Pharmaceutical Co, Ltd., Japan, PCORI, Perkin Elmer, Inc., Pfizer, Inc., Sanofi US, * Seattle Genetics,* Spectrum Pharmaceuticals, Inc., * St. Baldrick's Foundation, Sunesis Pharmaceuticals, Inc., * Swedish Orphan Biovitrum, Inc., Takeda Oncology, Telomere Diagnostics, Inc., the University of Minnesota, and Wellpoint, Inc.* (asterisk indicates corporate members).

The views expressed in this article do not reflect the official policy or position of the National Institutes of Health, the Department of the Navy, the Department of Defense, the Health Resources and Services Administration, or any other agency of the US Government.

\section{Authorship}

Contribution: L.M., A.A., M.C.P., R.B., M.M., X.Z., K.A., M.A., K.K.B., A. Bajel, F.B., M.B., A. Beitinjaneh, J.-Y.C., M.C., Y.-B.C., S. Chhabra, S. Ciurea, E.C., A.D., J.E., J.F., C.O.F., H.C.F., R.P.G., S.G., S.K.H., G.C.H., V.H., A.J., H.L., M.R.L., R. Martino, R. Maziarz, P.M., T.N., R.O., R.F.O., A.P., E.P., A.R.R., D.R., B.N.S., H.C.S., M. Sabloff, M. Seftel, S.S., M.L.S., J.S., B.M.W., and W.A.W. designed research; L.M., A.A., M.C.P., R.B., M.M., and X.Z. performed research; L.M., A.A., M.C.P., R.B., M.M., X.Z., K.A., M.A., K.K.B., A. Bajel, F.B., M.B., A. Beitinjaneh, J.-Y.C., M.C., Y.-B.C., S. Chhabra, S. Ciurea, E.C., A.D., J.E., J.F., C.O.F., H.C.F., R.P.G., S.G., S.K.H., G.C.H., V.H., A.J., H.L., M.R.L., R. Martino, R. Maziarz, P.M., T.N., R.O., R.F.O., A.P., E.P., A.R.R., D.R., B.N.S., H.C.S., M. Sabloff, M. Seftel, S.S., M.L.S., J.S., B.M.W., and W.A.W. analyzed and interpreted data; R.B., M.M., and X.Z. performed statistical analysis; and L.M., A.A., M.C.P., R.B., M.M., and X.Z. wrote the manuscript.

Conflict-of-interest disclosure: The authors declare no competing financial interests.

Correspondence: Lori Muffly, Stanford University, 300 Pasteur Dr, H0144B, Stanford, CA 94305; e-mail: 1muffly@stanford.edu.

\section{References}

1. Armitage JO. Bone marrow transplantation. N Engl J Med. 1994;330(12):827-838.

2. McSweeney PA, Niederwieser D, Shizuru JA, et al. Hematopoietic cell transplantation in older patients with hematologic malignancies: replacing high-dose cytotoxic therapy with graft-versustumor effects. Blood. 2001;97(11):3390-3400.

3. van Besien K, Artz A, Stock W. Unrelated donor transplantation over the age of 55 . Are we merely getting (b)older? Leukemia. 2005;19(1):31-33.

4. Lee SJ, Klein J, Haagenson M, et al. Highresolution donor-recipient HLA matching contributes to the success of unrelated donor marrow transplantation. Blood. 2007;110(13): 4576-4583.

5. D'Souza A, Zhu X. Current Uses and Outcomes of Hematopoietic Cell Transplantation (HCT): CIBMTR Summary Slides, 2016. Available at: https://www.cibtmr.org. Accessed 1 February 2017.

6. Chevallier P, Szydlo RM, Blaise D, et al. Reduced-intensity conditioning before allogeneic hematopoietic stem cell transplantation in patients over 60 years: a report from the SFGM-TC. Biol Blood Marrow Transplant. 2012;18(2):289-294.

7. McClune BL, Weisdorf DJ, Pedersen TL, et al. Effect of age on outcome of reduced-intensity hematopoietic cell transplantation for older patients with acute myeloid leukemia in firs complete remission or with myelodysplastic syndrome. J Clin Oncol. 2010;28(11):1878-1887.

8. Schetelig J, Bornhäuser M, Schmid C, et al. Matched unrelated or matched sibling donors result in comparable survival after allogeneic stem-cell transplantation in elderly patients with acute myeloid leukemia: a report from the cooperative German Transplant Study Group. $J$ Clin Oncol. 2008;26(32):5183-5191.

9. Lim Z, Brand R, Martino R, et al. Allogeneic hematopoietic stem-cell transplantation for patients 50 years or older with myelodysplastic 
syndromes or secondary acute myeloid leukemia. J Clin Oncol. 2010;28(3):405-411.

10. Wallen H, Gooley TA, Deeg HJ, et al. Ablative allogeneic hematopoietic cell transplantation in adults 60 years of age and older. J Clin Oncol. 2005;23(15):3439-3446.

11. Sorror ML, Sandmaier BM, Storer BE, et al. Longterm outcomes among older patients following nonmyeloablative conditioning and allogeneic hematopoietic cell transplantation for advanced hematologic malignancies. JAMA. 2011;306(17): 1874-1883.

12. Heidenreich S, Ziagkos D, de Wreede LC, et al Allogeneic stem cell transplantation for patients age $\geq 70$ years with myelodysplastic syndrome: a retrospective study of the MDS Subcommittee of the Chronic Malignancies Working Party of the EBMT. Biol Blood Marrow Transplant. 2017;23(1): 44-52.

13. Koroukian SM, Murray P, Madigan E. Comorbidity, disability, and geriatric syndromes in elderly cancer patients receiving home health care. J Clin Oncol. 2006;24(15):2304-2310.

14. Gale CR, Cooper C, Sayer AA. Prevalence of frailty and disability: findings from the English Longitudinal Study of Ageing. Age Ageing. 2015; 44(1):162-165.

15. Wildiers $\mathrm{H}$, Heeren $\mathrm{P}$, Puts $\mathrm{M}$, et al. International Society of Geriatric Oncology consensus on geriatric assessment in older patients with cancer. J Clin Oncol. 2014;32(24):2595-2603.

16. Lichtman SM. Therapy insight: therapeutic challenges in the treatment of elderly cancer patients. Nat Clin Pract Oncol. 2006;3(2):86-93.

17. Pasquini MC, Wang Z, Horowitz M, et al. 2013 Report from the Center for International Blood and Marrow Transplant Research (CIBMTR): current uses and outcomes of hematopoietic cell transplant for blood and bone marrow disorders. In: Everly JE, Terazaki PI, eds. Clinical Transplants 2013. Los Angeles: The Terasaki Foundation Laboratory; 2014:187-198.
18. American Society for Blood and Marrow Transplant. ASBMT RFI 2016: Disease Classifications Corresponding to CIBMTR Classifications. Available at: http://asbmt.org/ sites/default/files/asbmt_admin/ ASBMT_RFI_2016_CIBMTR_Diseas.pdf. Accessed 1 February 2017.

19. Bacigalupo A, Ballen K, Rizzo D, et al. Defining the intensity of conditioning regimens: working definitions. Biol Blood Marrow Transplant. 2009; 15(12):1628-1633.

20. Giralt S, Ballen K, Rizzo D, et al. Reducedintensity conditioning regimen workshop: defining the dose spectrum. Report of a workshop convened by the center for international blood and marrow transplant research. Biol Blood Marrow Transplant. 2009;15(3):367-369.

21. Armand P, Kim HT, Logan BR, et al. Validation and refinement of the Disease Risk Index for allogeneic stem cell transplantation. Blood. 2014; 123(23):3664-3671.

22. Sorror ML, Maris MB, Storb R, et al. Hematopoietic cell transplantation (HCT)-specific comorbidity index: a new tool for risk assessment before allogeneic HCT. Blood. 2005;106(8): 2912-2919.

23. Atallah E, Horowitz MM, Logan B, et al. Outcome of patients 65 years and older with myelodysplastic syndrome (MDS) receiving allogeneic hematopoietic stem cell transplantation compared to patients 55-64 years of age. Blood. 2015;126(23):193.

24. Abecassis M, Bridges ND, Clancy CJ, et al. Solidorgan transplantation in older adults: current status and future research. Am J Transplant. 2012;12(10):2608-2622.

25. Auner HW, Garderet L, Kröger N. Autologous haematopoietic cell transplantation in elderly patients with multiple myeloma. $\mathrm{Br} J$ Haematol. 2015;171(4):453-462.

26. Oran B, Weisdorf DJ. Survival for older patients with acute myeloid leukemia: a population-based study. Haematologica. 2012;97(12):1916-1924.
27. Brunner AM, Kim HT, Coughlin E, et al. Outcomes in patients age 70 or older undergoing allogeneic hematopoietic stem cell transplantation for hematologic malignancies. Biol Blood Marrow Transplant. 2013;19(9):1374-1380.

28. Dinmohamed AG, Visser $O$, van Norden $Y$, et al Treatment, trial participation and survival in adult acute myeloid leukemia: a population-based study in the Netherlands, 1989-2012. Leukemia. 2016; 30(1):24-31.

29. Krenger W, Blazar BR, Holländer GA. Thymic T-cell development in allogeneic stem cell transplantation. Blood. 2011;117(25):6768-6776.

30. Chaudhry MS, Velardi E, Malard F, van den Brink MR. Immune reconstitution after allogeneic hematopoietic stem cell transplantation: time to T up the thymus. J Immunol. 2017;198(1):40-46.

31. Muffly LS, Boulukos M, Swanson K, et al. Pilo study of comprehensive geriatric assessment (CGA) in allogeneic transplant: CGA captures a high prevalence of vulnerabilities in older transplant recipients. Biol Blood Marrow Transplant. 2013;19(3):429-434.

32. Artz AS, Chow S. Hematopoietic cell transplantation in older adults: deciding or decision-making? Bone Marrow Transplant. 2016; 51(5):643-644

33. Walter RB, Gyurkocza B, Storer BE, et al. Comparison of minimal residual disease as outcome predictor for AML patients in first complete remission undergoing myeloablative or nonmyeloablative allogeneic hematopoietic cell transplantation. Leukemia. 2015;29(1):137-144.

34. Mrózek K, Marcucci G, Nicolet D, et al. Prognostic significance of the European LeukemiaNet standardized system for reporting cytogenetic and molecular alterations in adults with acute myeloid leukemia. J Clin Oncol. 2012;30(36):4515-4523.

35. Greenberg PL, Tuechler H, Schanz J, et al. Revised international prognostic scoring system for myelodysplastic syndromes. Blood. 2012; 120(12):2454-2465. 


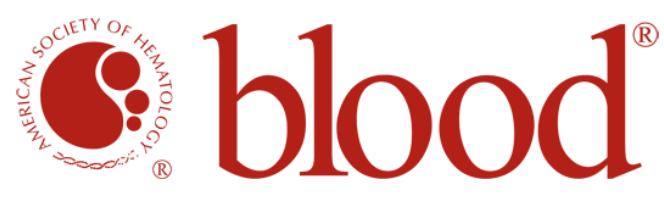

2017 130: 1156-1164

doi:10.1182/blood-2017-03-772368 originally published online July 3, 2017

\section{Increasing use of allogeneic hematopoietic cell transplantation in patients aged $\mathbf{7 0}$ years and older in the United States}

Lori Muffly, Marcelo C. Pasquini, Michael Martens, Ruta Brazauskas, Xiaochun Zhu, Kehinde Adekola, Mahmoud Aljurf, Karen K. Ballen, Ashish Bajel, Frederic Baron, Minoo Battiwalla, Amer Beitinjaneh, Jean-Yves Cahn, Mathew Carabasi, Yi-Bin Chen, Saurabh Chhabra, Stefan Ciurea, Edward Copelan, Anita D'Souza, John Edwards, James Foran, Cesar O. Freytes, Henry C. Fung, Robert Peter Gale, Sergio Giralt, Shahrukh K. Hashmi, Gerhard C. Hildebrandt, Vincent Ho, Ann Jakubowski, Hillard Lazarus, Marlise R. Luskin, Rodrigo Martino, Richard Maziarz, Philip McCarthy, Taiga Nishihori, Rebecca Olin, Richard F. Olsson, Attaphol Pawarode, Edward Peres, Andrew R. Rezvani, David Rizzieri, Bipin N. Savani, Harry C. Schouten, Mitchell Sabloff, Matthew Seftel, Sachiko Seo, Mohamed L. Sorror, Jeff Szer, Baldeep M. Wirk, William A. Wood and Andrew Artz

Updated information and services can be found at:

http://www.bloodjournal.org/content/130/9/1156.full.html

Articles on similar topics can be found in the following Blood collections

Transplantation (2335 articles)

Information about reproducing this article in parts or in its entirety may be found online at:

http://www.bloodjournal.org/site/misc/rights.xhtml\#repub_requests

Information about ordering reprints may be found online at:

http://www.bloodjournal.org/site/misc/rights.xhtml\#reprints

Information about subscriptions and ASH membership may be found online at:

http://www.bloodjournal.org/site/subscriptions/index.xhtml

Blood (print ISSN 0006-4971, online ISSN 1528-0020), is published weekly by the American Society of Hematology, 2021 L St, NW, Suite 900, Washington DC 20036.

Copyright 2011 by The American Society of Hematology; all rights reserved. 